\title{
Blaming The Words "Population" and "Community" Has Outlived Its Usefulness in Ecology - a Reply to Magnusson (2013)
}

\author{
Paulo Inácio Prado ${ }^{1 *} \&$ Charbel N. El-Hani²
}

\author{
${ }^{1}$ LAGE do Departamento de Ecologia, Instituto de Biociências, Universidade de São Paulo - USP, São Paulo, SP, Brasil \\ ${ }^{2}$ Laboratório de Ensino, Filosofia e História da Biologia - LEFHBio, Departamento de Biologia Geral, \\ Instituto de Biologia, Universidade Federal da Bahia - UFBA, Salvador, BA, Brasil
}

\begin{abstract}
This is an accompanying commentary on the paper by William Magnusson which proposes that the words "population" and "community" should be avoided by ecologists because they impair communication and scientific progress. This reasoning rests on a weak assumption that words with multiple meanings are a linguistic anomaly and cause a lack of progress in ecology and that there are absolute, context-free prescriptions on the use of terminology. We propose that scientists generally know how to address words with multiple meanings, and use them as far as they are useful, and, usually, but not always in their appropriate domains or contexts. In fact, the terms "population" and "community" have been increasingly used and currently occur in two thirds of published papers in leading ecology journals.
\end{abstract}

Key words: Population Ecology, Community Ecology, Polyssemy, Terminology, Paradigms, Scientific Progress.

\section{Introduction}

To blame the vagueness of key terms is a popular type of criticism in ecological literature. Since 1980 at least 63 terminological reviews were published including four critiques for the word "community" and seven for "population" (Hodges 2008). Terminology reviews in ecology are easily recognized as a genre. They (1) start by reviewing the use of an important term by ecologists and point out its multiple meanings, (2) propose that this semantic vagueness hinders communication, which hampers the advance of theory and its application, and (3) prescribe rules to solve the problem (Hodges 2008). Magnusson (2013) follows these three points to propose the abolition of the terms "population" and "community" from ecology. We evaluate each point and conclude that these terms are still useful.

\section{Are Words with Multiple Meanings a Communication Problem?}

Ecologists use the words "population" and "community" to name different things, but is that a linguistic anomaly? The answer is yes if you impose a one-to-one correspondence between words and concepts, which is the same as assuming

\footnotetext{
${ }^{\star}$ Send correspondence to: Paulo Inácio Prado

LAGE do Departamento de Ecologia, Instituto de Biociências,

Universidade de São Paulo - USP, Rua do Matão travessa 14,

321, CEP 05508-900, São Paulo, SP, Brasil

E-mail: prado@ib.usp.br
}

that words have absolute meanings. This is the Aristotelian view of definitions, to which Magnusson (2013) adheres when he asserts that "population" and "community" mean nothing because they can mean many things. However, there is no such thing like a 'real meaning' for words. In natural languages meanings vary among groups of users and contexts (polysemy). That is why semiotics distinguishes signs from the things they refer to, and recognize that polysemy is a feature of any language, rather than an anomaly. That is also why the semantic dimension of language is taken to be dependent on the pragmatic dimension: the meanings of words depend on how they are used.

One can argue, then, that polysemous terms indicate different contexts and a lack of scientific consensus. However, in this case polysemy is just a consequence, not the cause of the problem. Regardless of whether a consensus exists or not, and even of whether a consensus in a broad science like ecology is needed or desirable or not, there is still the risk of misunderstanding because of polysemy. Is that a important issue in research practice? Rarely, because humans are sensible to multiple contexts when communicating with each other, and scientists are trained to avoid ambiguities. For example, if "population" or "community" refers to a specific study system in a scientific paper, it is a truism that this system should be defined unequivocally. Another common use is to refer to a hierarchical level of ecological organization (see the third section), and it is common sense that this context of use should be clearly stated. 
Whatever the context, definitions are handy in allowing the use of a single word or short expression (the definiendum) as a shortcut for a wordier statement, the definiens. Magnusson (2013) overlooks such utility:

"I urge you (especially reviewers and editors) to try eliminating "population" and "community" from texts wherever is possible and see if it does not improve communication between writers and readers, $[\ldots]$ ".

However, avoidance of definienda makes texts more verbose, and this in fact impairs communication. Therefore, editors and reviewers would hardly embrace the censoring of "population" or "community".

\section{Have Words with Multiple Meanings Hindered the Progress of Ecology?}

Magnusson (2013) attributes the little progress in ecology to communication problems ensued by the terms "population" and "ecology". In the next paragraph, we evaluate the assumption of a lack of progress. However, let us assume that it is true for a scientific field for now. Suppose also that polysemy occurs in this field (a reasonable assumption, because polysemy occurs in any language). These two conditions are necessary, but not sufficient to conclude that polysemy hampered progress. The implication should be proven; otherwise the argument resumes to taking a correlation as causation. Most of the reviews of ecological terms incur in this fallacy (Hodges 2008) as Magnusson (2013) does because he does not provide any evidence that polysemous terms are the cause of an assumed lack of progress.

However, how far has ecology advanced in the last decades? A favorite sport of ecologists is to deplore the limited progress made by theoretical and applied ecology (e.g., Shrader-Frechette \& McCoy 1993). Magnusson (2013) endorses this view, and points out that "there was surprisingly little advance in community ecology in the last 30 years" because "the basics questions remains the same" since the 1970's. Scientific progress is a controversial notion (Hacking 1983; Paine 2002); however, for our argument, it is enough to adopt the well-known framework of Kuhn (1970). According to this perspective, science progresses through the development of a research paradigm until shortcomings are enough to challenge the current view and promote a new one (Kuhn 1970). Basic questions of a scientific field define its current paradigm; therefore, if they remain the same for a given period of time, it is not a lack of progress, but merely that a scientific revolution has not occurred. Meanwhile, the paradigm may have expanded and improved, which was the case for population and community ecology.

The mathematical modeling paradigm that founded population ecology was challenged in the 1980's because of its ahistorical approach (Kingsland 1995). The critics ensued an integrative research program, on the role of local and regional processes in shaping populations and communities (Ricklefs 1987). Biogeography returned to the center of ecological explanations as well as observational studies at large scales, which paved the way for macroecology (Brown 1995).

Community ecology has also been a lively and fast-growing discipline. One of the best appraisals (Vellend 2010) proposes that community ecology is about four basic processes: selection, drift, speciation, and dispersal. It is a deliberate analogue of the "big four" processes in population genetics and an old and venerable framework in biology. Why keep this old view? Because it has proven to be a prolific source of new ideas. Vellend (2010) mapped his four questions in many key theories and concepts developed after the 1970's, such as the neutral theory of biodiversity, metacommunities, and the historical-regional framework already mentioned. The list of theoretical novelties is far from complete even if we add the hot topics on biodiversity and ecosystem functioning (Loreau 2010), complex networks and food web theory (McCann 2012), and metabolic theories (Harte 2011).

Many of the developments above mentioned were deep enough to be claimed as new paradigms. However, not all ecologists concurred, most likely because it is hard to trace a clear-cut line separating paradigm expansion from scientific revolution in ecology (Paine 2002). Even so, there is plenty of evidence that ecology advanced considerably over the last few decades. The next section shows that ecologists have increasingly used the words "population" and "ecology" while all of this progress occurred.

\section{Should we Eliminate the Terms "Population" and "Community" from Ecological Literature?}

Terminology reviews end up with prescriptions, and Magnusson (2013) adopts a radical one: to eliminate the words "population" and "community" from scientific publications in ecology. The final conclusion is that the abolition "[...] may be the most effective method to increase the utility of the results of conservation studies." Nevertheless, nearly two-thirds of articles published in leading journals in the last two decades use the words "population" and/or "community", and this proportion has increased with time (Figure 1). The words "population" and/or "community" are also used to define the scope of prestigious publications such as Annual Review of Ecology Systematics and Evolution, Journal of Ecology, Ecology, Evolution, and Ecography. As a final example, the British Ecological Society used their centenary to prompt a list of the 100 most fundamental unanswered questions in ecology, through a broad consultation of distinguished ecologists (Sutherland et al. 2013). The resulting questions were grouped into six main subjects, which included "population" and "community and diversity" (16 and 20 questions, respectively).

Are we facing a huge collective mistake? Magnusson (2013) thinks so, because many ecologists have "strong feelings" 


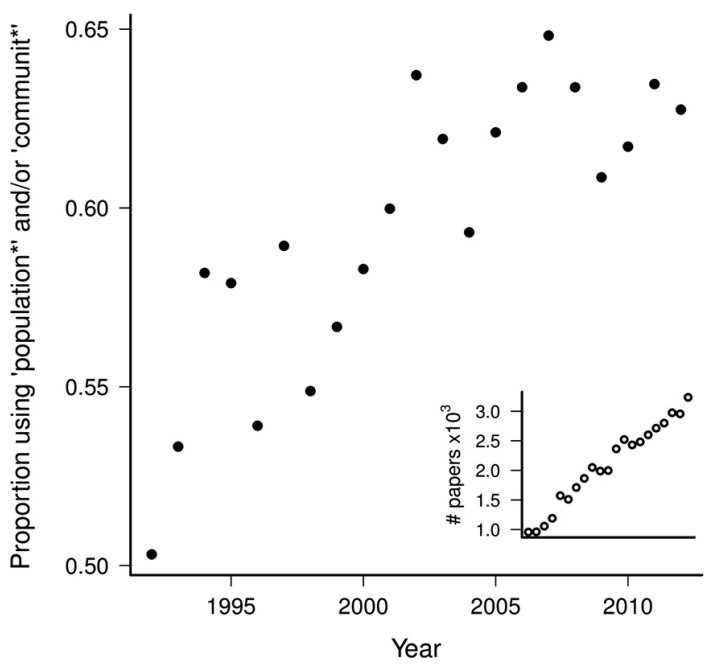

Figure 1. Main graph - Proportion of papers published in leading ecology journals that have the words "population"(s) and/or "community"(ies) in their titles, keywords or abstracts, from 1992 to 2012. Inset graph - number of published papers in the same journals for the same period. Database: the 20 journals in ecology with the highest impact factor in the last five years, according to the ISI Journal Citation Report: AREES, Trend Ecol Evol, Ecol Lett, Front Ecol Envir, Global Change Biol, Isme J, Ecol Monogr, Global Ecol Biogeogr, Mol Ecol, Bu Am Nat Hist, J Ecol, Ecology, Cons Biol, J Appl Ecol, P R Soc Lond B, Evolution, Ecography, Ecol Appl, Am Nat, and Persp Plant Ecol Evol Syst. Search criteria: articles published in each year with the terms "population*" and "communit" as a main topic (ISI Web of Science advanced search: TS $=\left(\right.$ population ${ }^{\star}$ OR communit $^{*}$ ) AND Document Types $=($ Article $)$ AND PY $=[$ year of publication]). Searches done on 6 May 2013.

about the words "population" and "community", much alike a religious person is emotionally bound to the word "god". We offer a more parsimonious hypothesis: scientists keep using a term while they find it useful in their research contexts. Therefore, the choice of vocabulary may be more rational and pragmatic than emotional. For example, the term "phlogiston" is useless for modern chemistry, and was gradually abandoned by chemists since the end of the XVIII century. We could gather this example from the history of science because "phlogiston" is still used in this field (as well as "god", by the way). Obviously, historians are not more emotional about these words than chemists are; they just need them to undertake their science. In summary, terms disappear from the scientific lexicon due to disuse and not by decree. The ecological lexicon did change over time (Nobis \& Wohlgemuth 2004), but "population" and "community" endured. They are used as definienda of specific study systems, or to refer to broad levels of ecological organization. Both usages fit many contexts of research and application in ecology.

\section{Conclusions}

Formal approaches such as in Magnusson (2013) try to solve ambiguities by prescribing context-free, fixed categories (Levins 1993). In this commentary, we emphasized a process-based approach - categories are created, mixed and reformulated as scientists interact among them and with other social actors (Levins 1993). In some contexts, polysemy does not lead to ambiguity and semantic confusion. In other contexts, however, it might. However, to charge polysemy in itself as a problem for communication it is necessary to show that it is indeed causing difficulties related to ambiguity and semantic confusion. In a science like ecology, with several subdisciplines, this means to develop an encompassing research project on how the words are used in scientific practice in those different fields. In our view, Dr. Magnusson did not achieve this goal.

In another context where polysemy has been accused of hampering scientific progress, it became clear that it was leading to semantic confusion and ambiguity, but proposals to simply eliminate the word were not well accepted. For example, some argued that that we should abandon the term "gene" (e.g., Keller 2000). Part of the problem is the diversity of meanings ascribed to genes. But, instead of demanding a single meaning for the term "gene", the term "gene" can have an heterogeneous reference potential without doing harm, provided that different meanings are useful for different research goals especially if they are kept properly separated (Kitcher 1982).

Accordingly, in our view, when we face polysemy, we do not need to throw words out, but to clearly demarcate between different models and concepts, so as to make it clear what are their domains of applicability, and, thus, the limits beyond which they are no longer appropriate. Rather than absolute meanings for words, we may need a plurality of views about what a given concept means (El-Hani 2007). If we take the case of the gene as an inspiration, we can say that we neither need a single meaning for "population" or "community", nor to just abandon these terms. Rather, we need to investigate the way these words are used by scientists in different fields of ecology, trying to identify potential misunderstandings, ambiguities, semantic confusions, and, at the same time, to distinguish between different meanings appropriate to different research contexts. Maybe, after doing so, we might conclude that these words are beyond hope. Our guess, however, is that the most likely outcome of such important study will be a proposal for a proper demarcation between meanings ascribed to these words in order to deal with different research and application targets. Therefore, let "population" and "community" be, while they are useful. When they were no longer useful, they will eventually disappear.

\section{Acknowledgements}

As with many other ecologists in Brazil, we are grateful to Bill Magnusson and his provocative persona in making us think critically about science. Our thanks also to the editors of N\&C for the invitation to write this commentary. We thank the Brazilian, São Paulo, and Bahia governments for research grants (CNPq 305326/2011-2 and FAPESP grants to P.I.P., CNPq 301259/2010-0 and FAPESB grants to C.N.H.). 


\section{References}

Brown JH, 1995. Macroecology. Chicago: University of Chicago Press.

El-Hani CN, 2007. Between the cross and the sword: the crisis of the gene concept. Genetics and Molecular Biology, 30:297307. http://dx.doi.org/10.1590/S1415-47572007000300001

Hacking I, 1983. Representing and Intervening. Cambridge: Cambridge University Press.

Harte J, 2011. Maximum entropy and ecology: a theory of abundance, distribution, and energetics. Oxford: OUP Oxford.

Hodges KE, 2008. Defining the problem: terminology and progress in ecology. Frontiers in Ecology and the Environment, 6:35-42. http://dx.doi.org/10.1890/060108

Keller EF, 2000. The Century of the Gene. Cambridge: Harvard University Press.

Kingsland SE, 1995. Modeling nature - Episodes in the History of Population Ecology. Chicago: University of Chicago Press.

Kitcher P, 1982. Genes. British Journal for the Philosophy of Science, 33:337-359. http://dx.doi.org/10.1093/bjps/33.4.337

Kuhn TS, 1970. The structure of scientific revolutions. Chicago: The University of Chicago Press.

Levins R, 1993. A response to Orzack and Sober: formal analysis and the fluidity of science. The Quarterly Review of Biology, 68:547-555. http://dx.doi.org/10.1086/418302
Loreau M, 2010. Linking biodiversity and ecosystems: towards a unifying ecological theory. Philosophical Transactions of the Royal Society B: Biological Sciences, 365:49-60. PMid:20008385 PMCid:2842700. http://dx.doi.org/10.1098/ rstb.2009.0155

Magnusson WE, 2013. The words "population" and "community" have outlived their usefulness in ecological publications. Natureza e Conservação, 11(1):1-8. http://dx.doi.org/10.4322/ natcon.2013.007

McCann KS, 2012. Food webs. Princeton: University Press.

Nobis M \& Wohlgemuth T, 2004. Trend words in ecological core journals over the last 25 years (1978-2002). Oikos, 106:411421. http://dx.doi.org/10.1111/j.0030-1299.2004.13496.x

Paine RT, 2002. Advances in ecological understanding: by Kuhnian revolution or conceptual evolution? Ecology, 83:1553-1559. http://dx.doi.org/10.1890/0012-9658(2002)083[1553:AIEU BK]2.0.CO;2

Ricklefs RE, 1987. Community diversity: relative roles of local and regional processes. Science, 235:167-171. PMid:17778629. http://dx.doi.org/10.1126/science.235.4785.167

Shrader-Frechette KS \& McCoy ED, 1993. Method in ecology: strategies for conservation. Cambridge: Cambridge University Press. http://dx.doi.org/10.1017/CBO9780511623394

Sutherland WJ et al., 2013. Identification of 100 fundamental ecological questions. Journal of Ecology, 101:58-67. http:// dx.doi.org/10.1111/1365-2745.12025

Vellend M, 2010. Conceptual synthesis in community ecology. The Quarterly review of biology, 85:183-206. PMid:20565040. http://dx.doi.org/10.1086/652373 